\title{
Comparison of transcatheter versus surgical aortic valve implantation in high-risk patients: A nationwide study in France
}

Xavier Armoiry, PharmD, PhD, ${ }^{\mathrm{a}, \mathrm{b}, \mathrm{c}}$ Jean-François Obadia, MD, PhD, ${ }^{\mathrm{d}}$ Léa Pascal, MPH, Stéphanie Polazzi, MSc, ${ }^{\text {e,f }}$ and Antoine Duclos, MD, PhD ${ }^{\text {,f,g }}$

\section{ABSTRACT}

Objective: To compare the clinical outcomes and direct costs at 5 years between transcatheter aortic valve implantation (TAVI) and surgical aortic valve replacement (SAVR) using real-world evidence.

Methods: We performed a nationwide longitudinal study using data from the French Hospital Information System from 2009 to 2015. We matched, inside hospitals, 2 cohorts of adults who underwent TAVI or SAVR during 2010 on propensity score based on patient characteristics. Outcomes analysis included mortality, morbidity, and total costs and with a maximum 60-month follow-up. Clinical outcomes were compared between cohorts using hazard ratios (HRs) estimated from a Cox proportional hazards model for all-cause death, and from Fine and Gray's competing risk model for morbidity.

Results: Based on a cohort of 1598 patients (799 in each group) from 27 centers, a higher risk of death was observed after 1 year with TAVI compared with SAVR (16.8\% vs $12.8 \%$, respectively; HR, 1.33 ; $95 \%$ confidence interval [CI], 1.02 1.72 ) and was sustained up to 5 years $(52.4 \%$ vs $37.2 \%$; HR, $1.56 ; 95 \% \mathrm{CI}$, $1.33-1.84)$. At 5 years, the risk of stroke was increased (HR, 1.64; 95\% CI, 1.07-2.54) as was myocardial infarction (HR, 2.30; 95\% CI, 1.12-4.69) and pacemaker implantation (HR, 2.40; 95\% CI, 1.81-3.17) after TAVI. The hospitalization costs per patient at 5 years were $€ 69,083$ after TAVI and $€ 55,687$ after SAVR $(P<.001)$.

Conclusions: In our study, high-risk patients harbored a greater risk of mortality and morbidity at 5 years after TAVI compared with those who underwent SAVR and higher hospitalizations costs. Those results should encourage caution before expanding the indications of TAVI. (J Thorac Cardiovasc Surg 2018;156:1017-25)

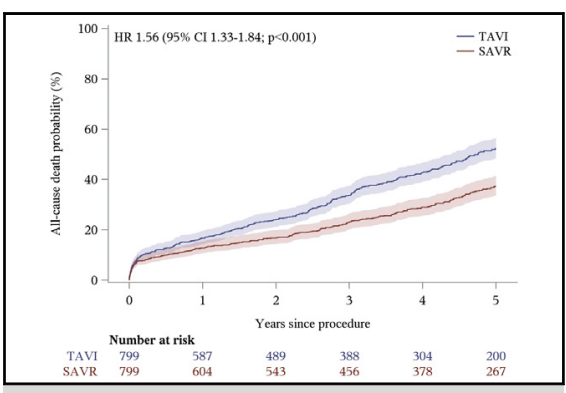

Cumulative probability of all-cause in-hospital mortality for transcatheter aortic valve implantation (TAVI) versus surgical aortic valve replacement (SAVR)

Central Message

Using real-world evidence, our study shows TAVI to be associated with a greater risk of mortality in patients with high surgical risk after 1 year that is sustained up to 5 years.

\section{Perspective}

The extension of TAVI for use in patients other than those with high or prohibitive surgical risk should be used with caution until further data, either based on RCTs or real-world evidence, are available on the relative long-term effectiveness of TAVI compared with SAVR.

See Editorial Commentary page 1026.

See Editorial page 1015.

\footnotetext{
From the a Division of Health Sciences, Warwick Medical School, University of Warwick, Coventry, England; ${ }^{b}$ Hospices Civils de Lyon/Quai des Célestins, Lyon, France; ${ }^{c}$ UMR-CNRS 5510/MATEIS, Lyon, France; ${ }^{\mathrm{d}}$ Service de Chirurgie Cardiothoracique et Transplantation, Hôpital Cardio-thoracique Louis Pradel, Lyon-Bron, Bron, France; ${ }^{e}$ Hospices Civils de Lyon, Pôle de Santé Publique, Service des Données de Santé, Lyon, France; ${ }^{\mathrm{f}}$ Université Claude Bernard Lyon 1, Health Services and Performance Research lab (HESPER EA7425), F-69008, Lyon, France; and ${ }^{g}$ Center for Surgery and Public Health, Brigham and Women's Hospital, Harvard Medical School, Boston, Mass

Received for publication Sept 5, 2017; revisions received Jan 12, 2018; accepted for publication Feb 12, 2018; available ahead of print May 12, 2018

Address for reprints: Xavier Armoiry, PharmD, PhD, Division of Health Sciences, Warwick Medical School, University of Warwick, Coventry, CV47AL United Kingdom (E-mail: armoiryxa@gmail.com).

$0022-5223 / \$ 36.00$

Copyright (C) 2018 by The American Association for Thoracic Surgery

https://doi.org/10.1016/j.jtcvs.2018.02.092
}

More than 15 years after the first-in-man case,,$^{1}$ transcatheter aortic valve implantation (TAVI) continues to revolutionize the management of severe aortic stenosis and has become a routinely performed procedure in cardiac centers worldwide. By early 2014, more than 100,000 of these procedures had been performed. ${ }^{2}$ Although the benefit

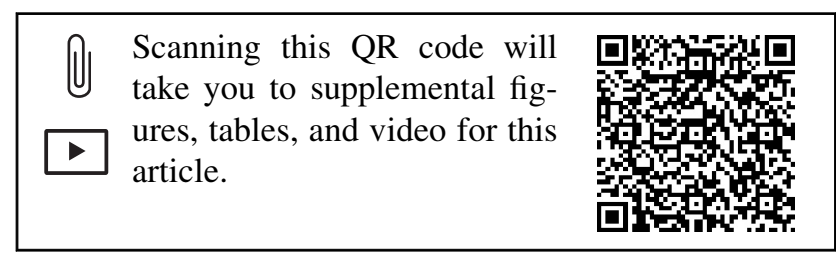




\section{Abbreviations and Acronyms \\ euroSCORE $=$ European system for cardiac operative risk evaluation \\ PSM \\ PMSI \\ RCT \\ SAVR \\ TAVI \\ $=$ propensity score matching \\ $=$ French Medical Information System \\ $=$ randomized controlled trial \\ $=$ surgical aortic valve replacement \\ $=$ transcatheter aortic valve implantation}

of TAVI was initially demonstrated in patients ineligible or at high surgical risk, ${ }^{3,4}$ a growing number of studies have evaluated TAVI in patients with low to intermediate risk. ${ }^{5,6}$ This has contributed to the currently observed trend toward expanded indications of TAVI in patients who would otherwise undergo surgical aortic valve replacement (SAVR). Several randomized controlled trials (RCTs) conducted among carefully selected populations have shown promising results on the clinical effectiveness and safety of TAVI compared with surgery. ${ }^{4,5,7}$ Conversely, evidence from real-world data indicate a better outcome with surgery compared with TAVI. ${ }^{8}$ Overall, the largest reported cohorts have a follow-up limited to 1 to 3 years in maximum, ${ }^{9,10}$ which is insufficient to provide a long-term view after aortic valve replacement.

Our nationwide study aimed to compare the long-term clinical outcomes and costs between patients undergoing TAVI and SAVR.

\section{MATERIAL AND METHODS Study Design and Participants}

We conducted a propensity-matched cohort study based on the French Medical Information System (PMSI). The PMSI is a large hospital database with prospectively collected data from all public and private hospitals in France. The database is routinely implemented for the purpose of care reimbursement, leading to very strong accuracy and exhaustive collection of the data. As a consequence, no patients were lost to follow-up during the considered period. Moreover, the PMSI has a system of coding with strict variable definitions and a subset of records audited on a regular basis to avoid excessively high rates of coding errors. Inpatient stays are converted into 1 diagnosis-related group based on standard discharge abstracts containing compulsory information about the patient; primary and secondary diagnoses using the International Classification of Diseases, 10th revision; as well as procedure codes associated with the care provided.

We selected all adults who underwent TAVI or SAVR in French institutions between January 1, 2010, and December 31, 2010. To homogenize the study population, we only selected cases with a main diagnosis of heart failure or rheumatic or nonrheumatic aortic valve disease (International Classification of Diseases, 10th revision, codes I06*, I35*, or I50*). Patients aged $<18$ years, having experienced ambulatory care, or with data inaccuracies were not retained in final cohorts. Within the index hospitalization stay, we extracted patients' demographic and socioeconomic characteristics, comorbidities according to Charlson and/or Elixhauser algorithms, ${ }^{11}$ the type and emergency context of surgical procedure, and length of stay. We subsequently used patient-unique anonymous numbers to link his/her stays in acute and rehabilitation care, allowing the extraction of hospitalization-related data from 12 months preceding TAVI and SAVR to a maximum of 60 months thereafter.

\section{Outcomes}

The primary end point was in-hospital mortality from the index hospitalization up to 5 years following TAVI or SAVR. Other outcomes included

TABLE 1. Baseline characteristics of patients postmatching

\begin{tabular}{|c|c|c|c|}
\hline Characteristic & TAVI $(\mathbf{n}=799)$ & SAVR $(n=799)$ & Standardized difference \\
\hline Male sex & $427(53.4)$ & $434(54.3)$ & -0.018 \\
\hline Age, y & $81(76-85)$ & $81(77-85)$ & 0.002 \\
\hline Income, $€$ & $19,659(18,285-21,971)$ & $19,734(18,395-22,073)$ & -0.060 \\
\hline Days of hospitalization in the previous year & $11(4-23)$ & $10(4-24)$ & -0.006 \\
\hline Emergency procedure & $13(1.6)$ & $13(1.6)$ & 0.000 \\
\hline Congestive heart failure & $284(35.5)$ & $278(34.8)$ & 0.016 \\
\hline Cardiac arrhythmias & $420(52.6)$ & $427(53.4)$ & -0.018 \\
\hline Pulmonary circulation disorders & $63(7.9)$ & $76(9.5)$ & -0.058 \\
\hline Peripheral vascular disease & $90(11.3)$ & $93(11.6)$ & -0.012 \\
\hline Hypertension & $350(43.8)$ & $338(42.3)$ & 0.030 \\
\hline Chronic pulmonary disease & 89 (11.1) & $88(11.0)$ & 0.004 \\
\hline Diabetes & $155(19.4)$ & $176(22.0)$ & -0.065 \\
\hline Renal disease & $122(15.3)$ & $119(14.9)$ & 0.010 \\
\hline Liver disease & $23(2.9)$ & $21(2.6)$ & 0.015 \\
\hline Obesity & $71(8.9)$ & $62(7.8)$ & 0.041 \\
\hline Myocardial infarction & $52(6.5)$ & $44(5.5)$ & 0.042 \\
\hline Cerebrovascular disease & $69(8.6)$ & $79(9.9)$ & -0.043 \\
\hline
\end{tabular}

Values are presented as $\mathrm{n}(\%)$ or median (interquartile range). TAVI, Transcatheter aortic valve implantation; SAVR, surgical aortic valve replacement. 
TABLE 2. Compared clinical outcomes between transcatheter aortic valve implantation (TAVI) and surgical aortic valve replacement (SAVR) cohorts

\begin{tabular}{|c|c|c|c|c|c|c|}
\hline \multirow[b]{2}{*}{ Time } & \multicolumn{2}{|r|}{ TAVI $(n=799)$} & \multicolumn{2}{|c|}{$\operatorname{SAVR}(n=799)$} & \multirow[b]{2}{*}{$\begin{array}{c}\text { Hazard ratio } \\
(95 \% \text { confidence interval }) \dagger\end{array}$} & \multirow[b]{2}{*}{$P$ value } \\
\hline & $\begin{array}{l}\text { No. of } \\
\text { events }\end{array}$ & $\begin{array}{c}\% \\
(95 \% \text { confidence interval })^{*}\end{array}$ & No. of events & $\begin{array}{c}\% \\
(95 \% \text { confidence interval })^{*}\end{array}$ & & \\
\hline \multicolumn{7}{|c|}{ All-cause death } \\
\hline At $1 \mathrm{y}$ & 127 & $16.8(14.3-19.6)$ & 97 & $12.8(10.6-15.4)$ & $1.33(1.02-1.72)$ & .033 \\
\hline At $2 y$ & 177 & $24.2(21.2-27.5)$ & 124 & $16.8(14.3-19.7)$ & $1.47(1.17-1.84)$ & .001 \\
\hline At $3 y$ & 235 & $33.7(30.3-37.4)$ & 163 & $23.1(20.1-26.4)$ & $1.52(1.25-1.85)$ & $<.001$ \\
\hline At $4 \mathrm{y}$ & 286 & $42.8(39.0-46.7)$ & 196 & $29.0(25.6-32.6)$ & $1.58(1.32-1.89)$ & $<.001$ \\
\hline At $5 \mathrm{y}$ & 332 & $52.4(48.4-56.5)$ & 236 & $37.3(33.5-41.4)$ & $1.56(1.33-1.84)$ & $<.001$ \\
\hline \multicolumn{7}{|c|}{ Postoperative stay in intensive care unit/critical care unit } \\
\hline At $1 \mathrm{y}$ & 296 & $37.0(33.7-40.4)$ & 537 & $67.2(63.8-70.3)$ & $0.48(0.43-0.55)$ & $<.001$ \\
\hline At $2 y$ & 313 & $39.2(35.8-42.5)$ & 540 & $67.6(64.2-70.7)$ & $0.50(0.45-0.57)$ & $<.001$ \\
\hline At $3 \mathrm{y}$ & 326 & $40.8(37.4-44.2)$ & 548 & $68.6(65.2-71.7)$ & $0.51(0.46-0.57)$ & $<.001$ \\
\hline At $4 \mathrm{y}$ & 334 & $41.8(38.4-45.2)$ & 550 & $68.8(65.5-71.9)$ & $0.52(0.46-0.58)$ & $<.001$ \\
\hline At $5 \mathrm{y}$ & 340 & $42.6(39.1-45.9)$ & 556 & $69.6(66.3-72.6)$ & $0.52(0.46-0.58)$ & $<.001$ \\
\hline \multicolumn{7}{|c|}{ Reoperation } \\
\hline At $1 \mathrm{y}$ & 15 & $1.9(1.1-3.0)$ & 7 & $0.9(0.4-1.7)$ & $2.15(0.87-5.30)$ & .097 \\
\hline At $2 y$ & 16 & $2.0(1.2-3.2)$ & 7 & $0.9(0.4-1.7)$ & $2.29(0.94-5.60)$ & .069 \\
\hline At $3 y$ & 16 & $2.0(1.2-3.2)$ & 8 & $1.0(0.5-1.9)$ & $2.01(0.85-4.71)$ & .110 \\
\hline At $4 \mathrm{y}$ & 17 & $2.1(1.3-3.3)$ & 9 & $1.1(0.6-2.1)$ & $1.90(0.84-4.28)$ & .123 \\
\hline At $5 \mathrm{y}$ & 18 & $2.3(1.4-3.5)$ & 9 & $1.1(0.6-2.1)$ & $2.01(0.90-4.50)$ & .090 \\
\hline \multicolumn{7}{|l|}{ Stroke } \\
\hline At $1 \mathrm{y}$ & 19 & $2.4(1.5-3.6)$ & 7 & $0.9(0.4-1.7)$ & $2.73(1.14-6.53)$ & .024 \\
\hline At $2 y$ & 26 & $3.3(2.2-4.7)$ & 16 & $2.0(1.2-3.2)$ & $1.64(0.87-3.08)$ & .124 \\
\hline At $3 y$ & 40 & $5.0(3.6-6.7)$ & 23 & $2.9(1.9-4.2)$ & $1.76(1.05-2.94)$ & .031 \\
\hline At $4 \mathrm{y}$ & 47 & $5.9(4.4-7.7)$ & 27 & $3.4(2.3-4.8)$ & $1.76(1.10-2.84)$ & .020 \\
\hline At $5 \mathrm{y}$ & 55 & $6.9(5.3-8.8)$ & 34 & $4.3(3.0-5.8)$ & $1.64(1.07-2.54)$ & .025 \\
\hline \multicolumn{7}{|c|}{ Myocardial infarction } \\
\hline At $1 \mathrm{y}$ & 5 & $0.6(0.2-1.4)$ & 1 & $0.1(0.0-0.7)$ & $5.01(0.58-42.94)$ & .142 \\
\hline At $2 y$ & 13 & $1.6(0.9-2.7)$ & 4 & $0.5(0.2-1.2)$ & $3.27(1.06-10.06)$ & .039 \\
\hline At $3 y$ & 17 & $2.1(1.3-3.3)$ & 6 & $0.8(0.3-1.6)$ & $2.86(1.12-7.27)$ & .028 \\
\hline At $4 \mathrm{y}$ & 19 & $2.4(1.5-3.6)$ & 8 & $1.0(0.5-1.9)$ & $2.39(1.04-5.50)$ & .039 \\
\hline At $5 \mathrm{y}$ & 25 & $3.1(2.1-4.5)$ & 11 & $1.4(0.7-2.4)$ & $2.30(1.12-4.69)$ & .023 \\
\hline \multicolumn{7}{|c|}{ Pacemaker } \\
\hline At $1 \mathrm{y}$ & 116 & $14.5(12.2-17.1)$ & 39 & $4.9(3.5-6.5)$ & $3.19(2.23-4.56)$ & $<.001$ \\
\hline At $2 y$ & 125 & $15.6(13.2-18.3)$ & 48 & $6.0(4.5-7.8)$ & $2.80(2.01-3.91)$ & $<.001$ \\
\hline At $3 y$ & 137 & $17.1(14.6-19.8)$ & 60 & $7.5(5.8-9.5)$ & $2.47(1.82-3.35)$ & $<.001$ \\
\hline At $4 \mathrm{y}$ & 156 & $19.5(16.9-22.3)$ & 70 & $8.8(6.9-10.9)$ & $2.42(1.82-3.22)$ & $<.001$ \\
\hline At $5 \mathrm{y}$ & 163 & $20.4(17.7-23.3)$ & 74 & $9.3(7.4-11.4)$ & $2.40(1.81-3.17)$ & $<.001$ \\
\hline
\end{tabular}

TAVI, Transcatheter aortic valve implantation; SAVR, surgical aortic valve replacement. *Cumulative probability of event (95\% confidence interval) at time from the nonparametric (1- Kaplan-Meier) estimator for all-cause death; and from the nonparametric cumulative incidence functions estimator using competing risk of death for the other outcomes. †Hazard ratios (instantaneous rate of event for TAVI relative to SAVR at any time) ( $95 \%$ confidence interval) and $P$ value, estimated between time 0 and time point, from Cox proportional hazards model for all-cause death, and from Fine and Gray's competing risk model for the other outcomes. Matched-pairs design was taken into account with robust variance estimator.

the occurrence of postoperative admission in intensive ( $\geq 2$ nights) or critical care unit ( $\geq 5$ nights), reoperation, stroke, myocardial infarction, or pacemaker implantation.

Economic evaluation was performed from the hospital perspective based on the total number of hospitalization stays, days, and costs over 5 years in acute or rehabilitation care. We valued in euros the in-hospital medical resources consumptions using average expenditures as observed in the national cost scale for the medicine, surgery, and obstetrics sector.

\section{Statistical Analysis}

To control for the nonrandom assignment of patients to 1 of the 2 procedures, we formed matched pairs of TAVI and SAVR patients using propensity scores. First, propensity scores were estimated as the predicted probability of a patient undergoing TAVI using a logistic regression model, including the following covariates: sex, age (continuous, with linear, quadratic, and cubic terms), household income (continuous), number of days spent in acute care hospitalizations the year before the index stay (continuous, with linear, quadratic, and cubic terms), emergency procedure, and a selection of comorbidities (ie, congestive heart failure, cardiac arrhythmia, pulmonary circulation disorder, peripheral vascular disease, hypertension, chronic pulmonary disease, diabetes, renal disease, liver disease, obesity, myocardial infarction, and cerebrovascular disease). We then matched patients with the closest propensity score inside hospital to control for confounders at hospital level, using a greedy 1:1 algorithm without 


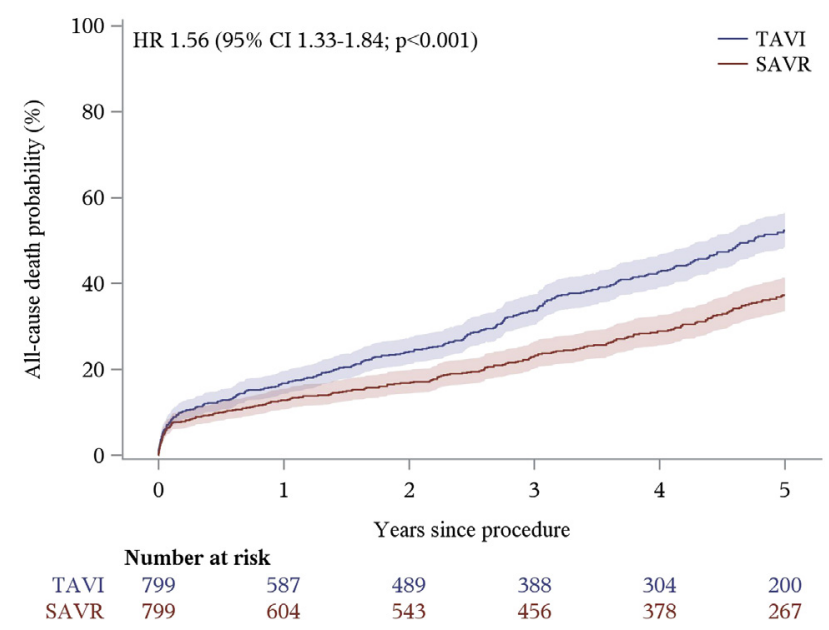

FIGURE 1. Cumulative probability of all-cause in-hospital mortality. Time varying outcome with shaded areas showing 95\% confidence intervals based on 1 Kaplan-Meier estimation of transcatheter aortic valve implantation (TAVI) versus surgical aortic valve replacement (SAVR). Shaded areas are $95 \%$ confidence intervals. $H R$, Hazard ratio; $C I$, confidence interval.

replacement and requiring that the logit of the propensity score of a patient who underwent TAVI and 1 who underwent SAVR be within 0.20 standard deviations of each another. Standardized differences were used to assess the degree of balance between the matched groups for baseline characteristics. An absolute standardized difference $\leq 0.10$ was chosen to indicate a negligible difference in the mean or prevalence of a variable between groups.
Balance for continuous variables was also assessed using graphic methods (side-by-side boxplots, empirical cumulative distribution functions, or empirical QQ plots) to compare the distributions across the 2 groups. Sensitivity analysis was conducted for the main outcomes (all-cause death and costs) with 1:1 nearest neighbor matching with replacement within caliper of 0.20 standard deviation of the logit of the propensity score, with the inclusion of weights in the outcome models (TAVI patients were weighted at 1 and the weight for a SAVR patient was the number of times it was matched to a TAVI patient).

Categorical variables were presented using absolute and relative frequencies and continuous variables were presented using medians and interquartile ranges. Estimates were accompanied with the corresponding $95 \%$ confidence interval (CI).

Clinical outcomes were assessed as time-to-event variables, and were evaluated at different time points ( 1 month, 6 months, then yearly up to 5 years after index procedure). Cumulative probabilities of events over time were estimated with the nonparametric 1 Kaplan-Meier estimator for all-cause death, and with the nonparametric cumulative incidence functions estimator using competing risk of death for postoperative stay in intensive or critical care unit, reoperation, stroke, myocardial infarction, and pacemaker. To compare the effect of procedure (TAVI vs SAVR), hazard ratios (HRs) were estimated between time 0 and another time point, from Cox proportional hazards model for all-cause death, and from Fine and Gray's model using competing risk of death for other clinical outcomes, with robust variance estimator to account for clustering within matched pairs. A sensitivity analysis was performed for the main clinical outcome (all-cause death) with a nested frailty model to take into account the 2 hierarchical levels of clustering (matched pairs nested within hospitals).

Health care use (eg, number of hospitalization stays, days, and costs) was assessed as count variables, and was evaluated at different time points. The rate of health care use per patient-year was the total number of health care uses in each procedure group divided by the total follow-up duration (date of the procedure until the date of death or end of the study period) of

TABLE 3. Compared health care use outcomes between transcatheter aortic valve implantation (TAVI) and surgical aortic valve replacement (SAVR) cohorts

\begin{tabular}{|c|c|c|c|c|c|c|c|c|}
\hline \multirow[b]{2}{*}{ Time } & \multicolumn{3}{|c|}{ TAVI $(\mathbf{n}=799)$} & \multicolumn{3}{|c|}{$\operatorname{SAVR}(\mathbf{n}=799)$} & \multirow[b]{2}{*}{$\begin{array}{c}\text { Rate ratio } \\
(95 \% \text { confidence } \\
\text { interval })^{*}\end{array}$} & \multirow[b]{2}{*}{$P$ value* } \\
\hline & $\begin{array}{c}\text { Total no. of health } \\
\text { care uses }\end{array}$ & $\begin{array}{c}\text { Total follow-up, } \\
\text { person-years }\end{array}$ & $\begin{array}{c}\text { Mean } \\
\text { cumulative } \\
\text { no. per person* }\end{array}$ & $\begin{array}{l}\text { Total no. of } \\
\text { health } \\
\text { care uses }\end{array}$ & $\begin{array}{c}\text { Total follow-up, } \\
\text { person-years }\end{array}$ & $\begin{array}{c}\text { Mean } \\
\text { cumulative } \\
\text { no. per person* }\end{array}$ & & \\
\hline \multicolumn{9}{|c|}{ No. of hospitalization stays } \\
\hline At $1 \mathrm{y}$ & 3184 & 703.61 & 4.51 & 3719 & 724.11 & 5.10 & $0.88(0.72-1.09)$ & .255 \\
\hline At 2 y & 4374 & 1349.18 & 6.46 & 5478 & 1411.32 & 7.71 & $0.84(0.64-1.10)$ & .200 \\
\hline At $3 y$ & 5526 & 1946.03 & 8.50 & 7222 & 2069.87 & 10.42 & $0.82(0.60-1.11)$ & .192 \\
\hline At 4 y & 6843 & 2480.04 & 11.02 & 8641 & 2689.18 & 12.81 & $0.86(0.61-1.20)$ & .381 \\
\hline At $5 \mathrm{y}$ & 7769 & 2969.54 & 13.07 & 10,097 & 3272.01 & 15.39 & $0.85(0.60-1.21)$ & .368 \\
\hline \multicolumn{9}{|c|}{ No. of days of hospitalization } \\
\hline At $1 \mathrm{y}$ & 35,809 & 703.61 & 50.04 & 43,040 & 724.11 & 58.16 & $0.86(0.79-0.94)$ & .001 \\
\hline At $2 y$ & 45,028 & 1349.18 & 65.05 & 51,836 & 1411.32 & 71.20 & $0.91(0.83-1.01)$ & .071 \\
\hline At $3 y$ & 53,527 & 1946.03 & 80.36 & 61,474 & 2069.87 & 86.17 & $0.93(0.84-1.03)$ & .177 \\
\hline At $4 \mathrm{y}$ & 61,887 & 2480.04 & 97.23 & 70,014 & 2689.18 & 100.72 & $0.97(0.87-1.07)$ & .514 \\
\hline At $5 \mathrm{y}$ & 68,434 & 2969.54 & 112.02 & 79,378 & 3272.01 & 116.93 & $0.96(0.86-1.07)$ & .432 \\
\hline \multicolumn{9}{|l|}{ Costs } \\
\hline At $1 \mathrm{y}$ & $30,774,212$ & 703.61 & 42,238 & $26,604,033$ & 724.11 & 35,128 & $1.20(1.13-1.28)$ & $<.001$ \\
\hline At $2 y$ & $35,123,650$ & 1349.18 & 49,330 & $30,183,988$ & 1411.32 & 39,917 & $1.24(1.15-1.33)$ & $<.001$ \\
\hline At $3 y$ & $39,051,054$ & 1946.03 & 56,102 & $34,014,554$ & 2069.87 & 45,031 & $1.25(1.15-1.35)$ & $<.001$ \\
\hline At $4 \mathrm{y}$ & $42,295,035$ & 2480.04 & 62,992 & $37,295,324$ & 2689.18 & 50,107 & $1.26(1.15-1.37)$ & $<.001$ \\
\hline At $5 \mathrm{y}$ & $44,889,719$ & 2969.54 & 69,083 & $40,860,170$ & 3272.01 & 55,687 & $1.24(1.13-1.36)$ & $<.001$ \\
\hline
\end{tabular}

TAVI, Transcatheter aortic valve implantation; SAVR, surgical aortic valve replacement. *From generalized estimating equations Poisson regression model. 


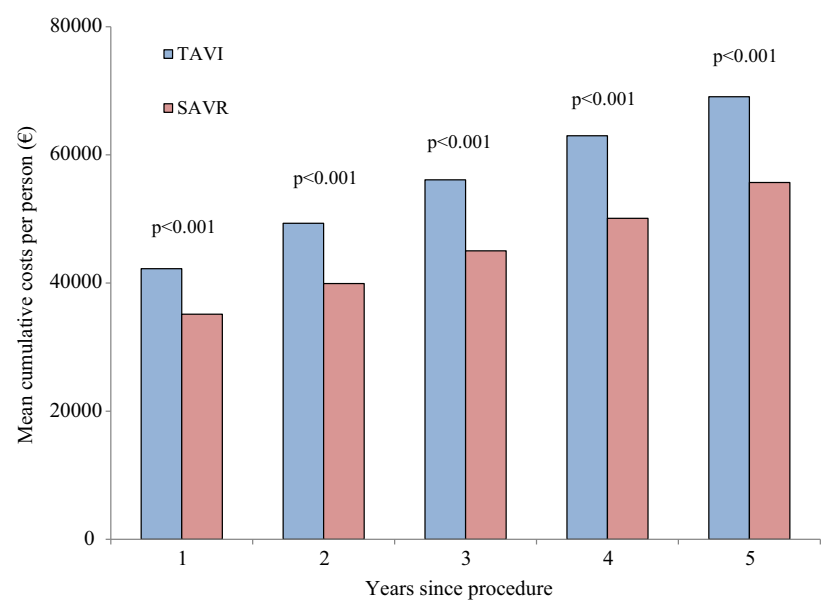

FIGURE 2. Mean cumulative costs over time. Predictions from generalized estimating equation Poisson regression model. TAVI, Transcatheter aortic valve implantation; $S A V R$, surgical aortic valve replacement.

all patients in that group between time 0 and another time point. The consequent rate ratio (RR) comparing TAVI to SAVR was estimated using generalized estimating equations with a log link, a Poisson distribution, and the $\log$ of the follow-up time as an offset. Robust standard errors were estimated using an independent or exchangeable working correlation structure and clustering on matched pairs to account for over dispersion (dependency within matched pairs and within patients experiencing repeated events). A sensitivity analysis was performed for the main economic outcome (costs) with a multilevel Poisson regression model to take into account the 2 hierarchical levels of clustering (matched pairs nested within hospitals). Mean cumulative numbers of health care use per person at a time point were estimated by multiplying the predicted rate by the time point. Sensitivity analyses were performed with a negative binomial distribution for all economic outcomes and with a gamma distribution for costs, providing RR estimations.

Data manipulation and analyses were performed using SAS version 9.4 (SAS Institute Inc, Cary, NC) and R version 3.3.2 (R Foundation for Statistical Computing, Vienna, Austria) software.

\section{Ethics Approval}

This study was strictly observational and we used anonymous data retrospectively. Therefore, in accordance to the French regulation on noninterventional clinical research, the written informed consent from the participants or the authorization from an ethical committee was not required.

\section{RESULTS}

\section{Participants/Descriptive Data}

During 2010, 1334 patients underwent TAVI and 6695 patients underwent SAVR at 27 French hospitals. After applying the selection and matching criteria, 799 pairs of patients were retained in the final analysis (Figure E1). Baseline characteristics of each cohort are listed in Table 1 with negligible difference between those (evolution pre- and postmatching is presented in the Table E1), and distribution of the propensity scores pre- and postmatching are represented in the Figure E2.

\section{Short-Term Clinical Outcomes}

The risk of hospital death from any cause at 30 days, 6 months, and 1 year was, respectively, 7.5\%, 12.7\%, and $16.8 \%$ in the TAVI group and $6.6 \%, 10.0 \%$, and $12.8 \%$ in the SAVR group, and was not different between both groups at 30 days and 6 months (HR, 1.15; 95\% CI, 0.79-1.68 and HR, 1.29; 95\% CI 0.96-1.73, respectively) but was higher after TAVI at 1 year (HR, 1.33; 95\% CI, 1.02-1.72).

At 1 year, there was no significant difference in the occurrence of reoperation ( $1.9 \%$ with TAVI vs $0.9 \%$ with SAVR) or myocardial infarction $(0.6 \%$ with TAVI vs $0.1 \%$ with SAVR), but the risk of stroke was higher after TAVI (2.4\% vs $0.9 \%$, respectively; $\mathrm{HR}, 2.73 ; 95 \% \mathrm{CI}, 1.14-6.53$ ) as was the risk of new pacemaker implantation $(14.5 \%$ vs $4.9 \%$, respectively; HR, 3.19; 95\% CI, 2.23-4.56).

\section{Long-Term Clinical Outcomes}

The cumulative probabilities and HR of each clinical outcome from 1 to 5 years are presented in Table 2, accompanied with the cumulative probability curves for death (Figure 1) and for the other clinical outcomes (Figure E3).

A higher risk of death was observed 2 years after TAVI compared with SAVR $(24.2 \%$ vs $16.8 \%$, respectively; HR, $1.47 ; 95 \%$ CI, 1.17-1.84) and sustained up to 5 years (52.4\% vs $37.3 \%$, respectively; HR, 1.56 ; $95 \%$ CI, 1.33 $1.84)$.

At 5 years, there was a trend toward a higher risk of reoperation after TAVI compared with SAVR $(2.3 \%$ vs $1.1 \%$ : HR, 2.01; 95\% CI, 0.90-4.50), whereas the risk of stroke significantly increased $(6.9 \%$ vs $4.3 \%$, respectively; HR, $1.64 ; 95 \% \mathrm{CI}, 1.07-2.54)$, as was myocardial infarction (3.1\% vs $1.4 \%$, respectively; HR, 2.30 ; $95 \%$ CI, 1.12 4.69) or new pacemaker implantation $(20.4 \%$ vs $9.3 \%$, respectively; HR, 2.40; 95\% CI, 1.81-3.17).

\section{Hospitalization Data and Cost Evaluation}

Hospitalization data and cost evaluation up to 5 years after the procedure are presented in Table 3 and Figure 2. At 1 year, the mean cumulative hospitalization costs per patient were $€ 42,238$ after TAVI and $€ 35,128$ after SAVR (RR, 1.20; 95\% CI, 1.13-1.28). The increased cost with TAVI was mainly attributed to the procedure performed during the index stay and was sustained up to 5 years (€69,083 vs $€ 55,687$, respectively; RR, $1.24 ; 95 \%$ CI, 1.13-1.36). The mean cumulative numbers of hospitalization stays and of days of hospitalization per patient were similar at any time in both groups, except for the mean cumulative number of days of hospitalization at 1 year, which was lower after TAVI (RR, 0.86; 95\% CI, 0.79-0.94).

\section{Sensitivity Analysis for the Main Outcomes}

Matching with replacement resulted in 1089 matchedpairs of TAVI and SAVR and the same trends for 
TABLE 4. Summary of studies identified in our literature search

\begin{tabular}{|c|c|c|c|c|c|c|c|c|c|c|c|c|c|c|c|c|c|}
\hline \multirow{3}{*}{$\begin{array}{c}\text { Author/study } \\
\text { name }\end{array}$} & \multirow[b]{3}{*}{ Inclusion period } & \multirow[b]{3}{*}{ Country } & \multirow[b]{3}{*}{ Centers } & \multirow{3}{*}{$\begin{array}{c}\text { Sample } \\
\text { size }\end{array}$} & \multirow{3}{*}{$\begin{array}{l}\text { Method of } \\
\text { comparison }\end{array}$} & \multirow[b]{3}{*}{ STS, \% } & \multirow{3}{*}{$\begin{array}{c}\text { Logistic } \\
\text { euroSCORE } \\
\text { I, \% }\end{array}$} & \multicolumn{10}{|c|}{ All cause death, \% } \\
\hline & & & & & & & & \multicolumn{2}{|c|}{$1 \mathrm{y}$} & \multicolumn{2}{|c|}{$2 y$} & \multicolumn{2}{|c|}{$3 y$} & \multicolumn{2}{|c|}{$4 y$} & \multicolumn{2}{|c|}{$5 y$} \\
\hline & & & & & & & & TAVI & SAVR & TAVI & SAVR & TAVI & SAVR & TAVI & SAVR & TAVI & SAVR \\
\hline \multicolumn{18}{|l|}{ High-risk patients } \\
\hline Partner $1^{12-14}$ & 2007-2009 & USA & 25 & $348 / 351$ & RCT & $11.8 / 11.7$ & $29.3 / 29.2$ & \multicolumn{2}{|c|}{$P=.44$} & \multicolumn{2}{|c|}{$P=.78$} & \multicolumn{2}{|c|}{-} & \multicolumn{2}{|c|}{-} & $\begin{array}{l}67.8 \\
P=\end{array}$ & $\begin{aligned} & 62.4 \\
= & .76\end{aligned}$ \\
\hline US Corevalve $e^{7,15,16}$ & 2011-2012 & USA & 45 & $391 / 359$ & $\mathrm{RCT}$ & $7.3 / 7.5$ & $17.6 / 18.4$ & $P=.04$ & $\begin{array}{l}19.1 \\
.04\end{array}$ & $\begin{array}{r}22.2 \\
P=\end{array}$ & $\begin{array}{l}28.6 \\
.04\end{array}$ & $\begin{array}{l}32.9 \\
P=\end{array}$ & $\begin{array}{l}39.1 \\
.068\end{array}$ & & - & \multicolumn{2}{|c|}{-} \\
\hline Latib et al ${ }^{17}$ & $\begin{array}{r}2003-2008+ \\
2007-2011\end{array}$ & Italy & 1 & $111 / 111$ & PSM & $4.6 / 4.6$ & $23.2 / 24.4$ & \multicolumn{2}{|c|}{$\begin{array}{c}0.4 \\
P=.80\end{array}$} & \multicolumn{2}{|c|}{-} & \multicolumn{2}{|c|}{-} & & - & \multicolumn{2}{|c|}{-} \\
\hline $\begin{array}{l}\text { Piazza and } \\
\text { colleagues }^{10}\end{array}$ & 2006-2010 & 3 in $\mathrm{EU}$ & 3 & $405 / 405$ & PSM & - & $17.1 / 17.5$ & \multicolumn{2}{|c|}{$P=.93$} & & - & \multicolumn{2}{|c|}{-} & & - & \multicolumn{2}{|c|}{-} \\
\hline $\begin{array}{l}\text { Johansson and } \\
\text { colleagues }^{18}\end{array}$ & 1999-2014 & Sweden & 1 & $166 / 125$ & PSM & - & $23 / 20$ & \multicolumn{2}{|c|}{$P=.001$} & & - & & - & $\begin{array}{l}48.2 \\
P=\end{array}$ & $\begin{array}{c}27 \\
.001\end{array}$ & & - \\
\hline $\begin{array}{l}\text { Muneretto and } \\
\text { colleagues }^{19}\end{array}$ & 2007-2014 & EU & 7 & $204 / 204$ & PSM & $8.2 / 8.4$ & $19.5 / 19.2$ & $\begin{array}{l}9.9 \\
\quad P<\end{array}$ & $\begin{array}{c}3.3 \\
.001\end{array}$ & $\begin{aligned} 20.5 \\
P<\end{aligned}$ & $\begin{array}{r}8.7 \\
.001\end{array}$ & & - & & - & & - \\
\hline Our study & 2010 & France & 27 (nationwide) & 799/799 & PSM & - & - & $\begin{array}{l}16.8 \\
P=\end{array}$ & $\begin{array}{l}12.8 \\
.033\end{array}$ & $\begin{array}{l}24.2 \\
P=\end{array}$ & $\begin{array}{l}16.8 \\
.001\end{array}$ & $\begin{aligned} 33.7 & \\
P< & \end{aligned}$ & $\begin{array}{l}23.1 \\
.001\end{array}$ & $\begin{array}{l}42.8 \\
P<\end{array}$ & $\begin{array}{l}29.0 \\
.001\end{array}$ & $\begin{array}{l}52.4 \\
P<.\end{array}$ & $\begin{array}{l}37.3 \\
.001\end{array}$ \\
\hline Intermediate- to low-ri & k patients & & & & & & & & & & & & & & & & \\
\hline Notion $^{20,21}$ & 2009-2013 & Denmark & 3 & $145 / 135$ & RCT & $2.9 / 3.1$ & $8.4 / 8.9$ & $\begin{array}{l}4.9 \\
\qquad P=\end{array}$ & $\begin{array}{l}7.5 \\
.38\end{array}$ & $\begin{array}{r}8.0 \\
P=\end{array}$ & $\begin{array}{l}9.8 \\
.54\end{array}$ & & - & & - & & - \\
\hline Partner $2^{5}$ & 2011-2013 & USA & 57 & $1011 / 1021$ & $\mathrm{RCT}$ & $5.8 / 5.8$ & - & $\begin{array}{r}12.3 \\
P=\end{array}$ & $\begin{array}{l}12.9 \\
.69\end{array}$ & $\begin{array}{r}16.7 \\
P=\end{array}$ & $\begin{array}{l}18.0 \\
.45\end{array}$ & & - & & - & & - \\
\hline Surtavi $^{22}$ & 2012-2016 & $\begin{array}{l}\text { USA, Europe, } \\
\text { Canada }\end{array}$ & 87 & $879 / 867$ & $\mathrm{RCT}$ & $4.4 / 4.5$ & $11.9 / 11.6$ & 6.7 & $S^{6.8}$ & ${ }^{12.6}$ & $S^{14.0}$ & & - & & - & & - \\
\hline $\begin{array}{l}\text { Schymik and } \\
\text { colleagues }\end{array}$ & 2007-2012 & Germany & 1 & $216 / 216$ & PSM & - & $8.7 / 8.8$ & $\begin{array}{l}11.6 \\
P=\end{array}$ & $\begin{array}{r}7.4 \\
157^{*}\end{array}$ & $\begin{array}{l}17.1 \\
P=\end{array}$ & $\begin{array}{r}9.7 \\
157^{*}\end{array}$ & $\begin{array}{l}19.9 \\
P=\end{array}$ & $\begin{array}{r}14.3 \\
.157^{*}\end{array}$ & & - & & - \\
\hline $\begin{array}{l}\text { Rosato and } \\
\text { colleagues }^{23}\end{array}$ & 2010-2012 & Italy & 93 (nationwide) & $355 / 355$ & PSM & - & $6.3 / 6.3$ & $\begin{array}{l}11.4 \\
P=\text {. }\end{array}$ & $\begin{array}{r}7.8 \\
075^{*}\end{array}$ & $\begin{array}{l}19.6 \\
P=.\end{array}$ & $\begin{array}{l}12.8 \\
075^{*}\end{array}$ & $\begin{array}{l}28.0 \\
P=.\end{array}$ & $\begin{array}{r}16.6 \\
0075^{*}\end{array}$ & & - & & - \\
\hline $\begin{array}{l}\text { Thourani and } \\
\text { colleagues }^{24}\end{array}$ & $\begin{array}{l}2011-2013+ \\
2014\end{array}$ & USA, Canada & $51+57$ & 1077/944 & PSS & $5.2 / 5.4$ & - & $\begin{array}{r}7.4 \\
P=\end{array}$ & $\begin{array}{c}13.0 \\
0003\end{array}$ & & - & & - & & - & & - \\
\hline
\end{tabular}

STS, Society of Thoracic Surgeons; EuroSCORE, European system for cardiac operative risk evaluation; TAVI, transcatheter aortic valve implantation; SAVR, surgical aortic valve replacement; RCT, randomized controlled trial; $P S M$, propensity-score matching; $N S$, not significant; EU, European Union; PSS, propensity-score stratification. *Calculated over the 3-year period. †Estimated from the number of deaths stated in the manuscript (71 in TAVI, 67 in SAVR). 
all-cause death and costs, although effects were attenuated and results at 1 year up to 3 years became nonsignificant (Figure E4, Tables E2 and E3).

In the cohort matched without replacement, the nested frailty model for all-cause death resulted in very similar effects (Table E4), whereas the multilevel Poisson regression for costs did not converge.

\section{DISCUSSION}

\section{Principal Findings}

We used real-world data from a nationwide database, including $100 \%$ of the cases during the considered period, to compare the long-term clinical outcomes between TAVI and SAVR in 2 propensity score-matched cohorts of patients. Our findings showed an increased risk of death after TAVI at 1 year that increased up to $50 \%$ at 5 years. There were also much higher risks of stroke, myocardial infarction, and pacemaker implantation after TAVI with higher cumulated costs relating to the index hospitalization stay.

\section{Comparison With Other Studies}

The entire TAVI population $(\mathrm{n}=1274)$ that we identified from the database was also part of the France 2 French registry, which enrolled 3195 high-risk patients (mean Logistic Article Navigation European system for cardiac operative risk evaluation [euroSCORE] score $21 \% ; 74 \%$ with a Logistic euroSCORE $\geq 20 \%$ ) between January 2010 and October 2011. ${ }^{3}$ Although the entire SAVR population had a lower risk compared with the entire TAVI population, we selected a cohort of patients with much higher risk profile within the entire SAVR population. Hence, we assume that matching between these populations allowed us to compare similar cohorts of high-risk patients.

Our survival estimates are supported by a longer follow up and larger study sample than previous publications comparing the 2 procedures (Table 4). Among RCTs that included high-risk patients (Logistic euroSCORE 18\%-29\%), there was no significant difference on the risk of death at 3 years ${ }^{15}$ and 5 years. ${ }^{12}$ The results from our study in high-risk patients contrast greatly with those reported in these 2 RCTs. Although our study outcomes after TAVI were comparable to those in the US CoreValve (Medtronic, Minneapolis, Minn) RCT, the survival after SAVR was far better compared with US CoreValve. Among the 4 published propensity-score matching (PSM) cohort analyses that selected high-risk patients, 2 studies ${ }^{10,17}$ showed no difference in mortality after 1 year, whereas 2 other studies reported a greater mortality with TAVI from the first year and up to $2^{19}$ or $4^{18}$ years of follow-up. This increase in mortality with TAVI compared with SAVR is consistent with our findings and has been recently emphasized in a meta-analysis of studies that used PSM. ${ }^{8}$

The magnitude of the mortality increase after TAVI compared with SAVR raises the question on the comparability of TAVI and SAVR cohorts matched using PSM and will be further discussed. However, we believe that the systematic presence of unidentified confounders within health care databases used across different country settings is unlikely.

Although our study did only include high-risk patients, we also examined the published outcomes after TAVI or SAVR in people with intermediate-risk patients (Table 4) owing to the increase used of TAVI in this population.

Three RCTs that included people with a lower surgical risk reported a similar risk of mortality but to date the follow-up is limited to a maximum of 2 years. ${ }^{5,20-22}$ Two other studies using PSM in people with similar riskprofile showed a higher risk of death after TAVI at 3 years. ${ }^{9,23}$ Conversely, Thourani and colleagues ${ }^{24}$ reported reduced mortality after TAVI at 1 year but these latter results are subject to caution given the presence of several major methodologic flaws pertaining to the covariates that were included in the propensity score model. ${ }^{25}$

We observed an increased risk of stroke at 5 years with TAVI compared with SAVR. We cannot provide interpretation of these findings based on data pertaining to onset of postprocedural atrial fibrillation or use of anticoagulation regimen at follow-up. One might speculate that TAVI patients mostly received dual antiplatelet therapy with clopidogrel and aspirin, whereas SAVR patients received mostly vitamin $\mathrm{K}$ antagonists or just aspirin for 3 months. However, in the absence of formal recommendations on anticoagulation management, we believe there are lots of variations across centers.

Our study provides further information on hospital resource consumption between TAVI and SAVR. The cumulative costs were higher after TAVI, whereas there were no differences at 5 years regarding the number of stays or days consumed at hospital. Furthermore, the lower number of hospitalizations contrasts with the higher total costs at 1 year post-TAVI compared with SAVR, which can be explained by the cost of TAVI device during the index stay. Although our study was not designed as a costeffectiveness evaluation, our results showing a reduced survival and higher costs with TAVI suggest that TAVI would be dominated by SAVR.

\section{Limitations}

Our study carries several limitations. We identified 2 cohorts of patients from the French PMSI database, which is increasingly used in health service research given the exhaustive collection of medical information for the whole population of the country. ${ }^{26,27}$ To control for the nonrandom 


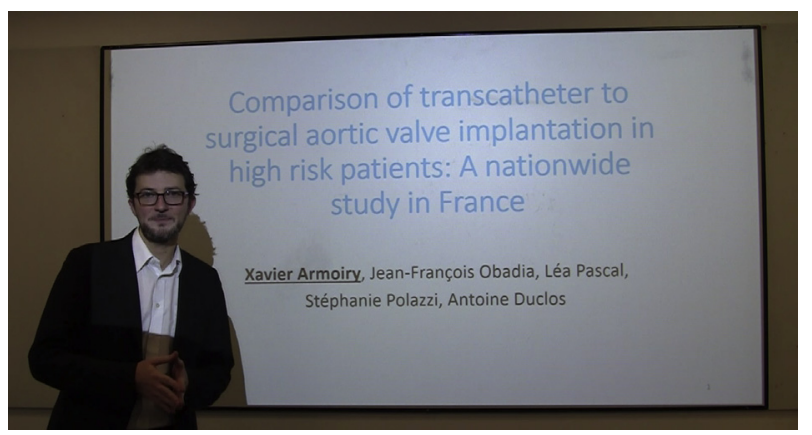

VIDEO 1. First author Dr Armoiry and second author Prof Obadia presenting the main results and discussing the practical implications of findings. Video available at: https://www.dropbox.com/s/6jfh55mabzja271/ jtcvs-17-1732R1.mp4?dl=0.

assignment of patients between TAVI and SAVR procedures, we used propensity-score matching adjustment based on a high number of patient characteristics and with control for confounders at hospital level. The risk of bias with PSM studies is to omit some potential confounders that can alter the comparability of populations and therefore threaten the validity of outcome measures. ${ }^{28}$ The PMSI database does not enable to precisely calculate the euroSCORE because the clinical variables that are available are not strictly those listed or are not as accurately defined among the factors that are accounted for in the euroSCORE calculation. Because data granularity did not allow us to accurately describe every patients profile with respect to the surgical risk, we added the number of hospitalization days in acute care consumed the year preceding the index stay to account for unmeasured confounders. Among variables available within the PMSI database, we chose in our propensity-score based method those with the most clinical relevance to discriminate the mortality/morbidity risk of populations but also accounting for those with a sufficient degree of validity. We are aware that the PMSI database variables may also lack of granularity to account for factors such as patient frailty or the complexity of the procedure.

A weakness of large hospital databases is the miscoding of diagnoses during hospital stays that can underestimate patients' comorbidities. ${ }^{29}$ This issue is not specific to a disease area or to certain type of procedure and is more influenced by a strong coding variability between health care providers and across years. Given this, we matched pairs of patients who underwent either TAVI or SAVR inside the same hospital and over the same period. Hence, we believe there is no a priori reason that miscoding would be more prominent in 1 cohort than another and would alter their comparability. Another limitation relates to our inability to capture deaths occurring outside a hospital, which means that the mortality rates might be slightly underestimated. However, the rate of death occurring outside hospitals is today extremely rare and probably negligible. There might also have been an underreporting of adverse events as suggested by the low incidence of stroke, myocardial infarction, or permanent pacemaker implantation observed in this study. Again, this issue is not specific to certain procedure type and we assume that the relative occurrence of these events between TAVI and SAVI was adequately estimated. Finally, the selected cohorts were treated during 2010; that is, 8 years ago, and may therefore be less representative of contemporary practices and outcomes related to TAVI in French centers because patient characteristics, devices, and experience of centers have surely evolved in recent years. However, this choice enabled us to provide the longest ever reported follow-up of TAVI patients based on real-world data.

\section{Practical Implications}

The 2017 guidelines from the European Society of Cardiology ${ }^{30}$ recommend considering TAVI in patients who are suitable for SAVR as assessed by a heart team but also an alternative to surgery in people who are at increased surgical risk, the decision being made by a heart team according to each patient's characteristics. Accounting for the results of the Placement of Aortic Transcatheter Valve (PARTNER) 2 trial, ${ }^{5}$ the recently updated American Hospital Association/American College of Cardiology guidelines extend the indication of TAVI to intermediate surgical risk depending on patient-specific procedural risks, values, and preferences. ${ }^{31}$ Based on these updated guidelines, the trend toward an expanded use of TAVI to patients with lower surgical risk is likely to get amplified to a great extent. As previously emphasized, the results from Partner 2 that suggest the noninferiority of TAVI and SAVR in intermediate-risk patients are only available at 2 years, which is notably insufficient to evaluate the long-term effectiveness of TAVI compared with SAVR, for which the outcomes are demonstrated beyond 20 years. Moreover, the results from Partner 2, ${ }^{5}$ along with those of Partner-high risk, ${ }^{12}$ may be not representative of real-world clinical outcomes. Our results showed an increased risk of mortality for TAVI compared to SAVR using a large nationwide database providing real-word evidence over a long-term perspective. The implication of our findings is that the extension of TAVI in patients other than those with high or prohibitive surgical risk should be cautious until further data, either based on RCTs or real-world evidence, are made available to inform on the relative long-term effectiveness of TAVI compared with SAVR.

\section{CONCLUSIONS}

Our study showed that patients after TAVI, compared with those who underwent SAVR, harbored a greater risk of mortality and morbidity at 5 years, and had higher costs 
of hospitalization. These results indicate that more data are needed before considering an enlargement of TAVI indications in people eligible for conventional surgery. The full article is discussed by the authors in Video 1.

\section{Conflict of Interest Statement}

Dr Obadia received personal fees from Edwards and Medtronic for activities conducted outside the submitted work. All other authors have nothing to disclose with regard to commercial support.

\section{References}

1. Cribier A. Historical perspective: 10th year anniversary of TAVI. EuroIntervention. 2012;8(Suppl Q):Q15-7.

2. Newton JD, Redwood S, Prendergast BD. Transcatheter aortic valve implantation: a durable treatment option in aortic stenosis? Heart. 2015;101:913-4.

3. Gilard M, Eltchaninoff H, Iung B, Donzeau-Gouge P, Chevreul K, Fajadet J, et al. Registry of transcatheter aortic-valve implantation in high-risk patients. $N$ Engl J Med. 2012;366:1705-15.

4. Leon MB, Smith CR, Mack M, Miller DC, Moses JW, Svensson LG, et al. Transcatheter aortic-valve implantation for aortic stenosis in patients who cannot undergo surgery. N Engl J Med. 2010;363:1597-607.

5. Leon MB, Smith CR, Mack MJ, Makkar RR, Svensson LG, Kodali SK, et al. Transcatheter or surgical aortic-valve replacement in intermediate-risk patients. N Engl J Med. 2016;374:1609-20.

6. Cribier A, Durand E, Eltchaninoff H. Patient selection for TAVI in 2014: is it justified to treat low- or intermediate-risk patients? The cardiologist's view. EuroIntervention. 2014;10(Suppl U):U16-21.

7. Adams DH, Popma JJ, Reardon MJ, Yakubov SJ, Coselli JS, Deeb GM, et al. Transcatheter aortic-valve replacement with a self-expanding prosthesis. $N$ Engl J Med. 2014;370:1790-8.

8. Ando T, Takagi H. Comparison of late mortality after transcatheter aortic valve implantation versus surgical aortic valve replacement: Insights from a meta-analysis. Eur J Intern Med. 2017;40:43-9.

9. Schymik G, Heimeshoff M, Bramlage P, Herbinger T, Wurth A, Pilz L, et al. A comparison of transcatheter aortic valve implantation and surgical aortic valve replacement in 1,141 patients with severe symptomatic aortic stenosis and less than high risk. Catheter Cardiovasc Interv. 2015;86:738-44.

10. Piazza N, Kalesan B, van Mieghem N, Head S, Wenaweser P, Carrel TP, et al. A 3-center comparison of 1-year mortality outcomes between transcatheter aortic valve implantation and surgical aortic valve replacement on the basis of propensity score matching among intermediate-risk surgical patients. JACC CardiovasC Interv. 2013;6:443-51.

11. Quan H, Sundararajan V, Halfon P, Fong A, Burnand B, Luthi JC, et al. Coding algorithms for defining comorbidities in ICD-9-CM and ICD-10 administrative data. Med Care. 2005;43:1130-9.

12. Mack MJ, Leon MB, Smith CR, Miller DC, Moses JW, Tuzcu EM, et al. 5-year outcomes of transcatheter aortic valve replacement or surgical aortic valve replacement for high surgical risk patients with aortic stenosis (PARTNER 1): a randomised controlled trial. Lancet. 2015;385:2477-84.

13. Kodali SK, Williams MR, Smith CR, Svensson LG, Webb JG, Makkar RR, et al. Two-year outcomes after transcatheter or surgical aortic-valve replacement. $N$ Engl J Med. 2012;366:1686-95.

14. Smith CR, Leon MB, Mack MJ, Miller DC, Moses JW, Svensson LG, et al. Transcatheter versus surgical aortic-valve replacement in high-risk patients. $N$ Engl J Med. 2011;364:2187-98.

15. Deeb GM, Reardon MJ, Chetcuti S, Patel HJ, Grossman PM, Yakubov SJ, et al. 3-Year outcomes in high-risk patients who underwent surgical or transcatheter aortic valve replacement. J Am Coll Cardiol. 2016;67:2565-74.

16. Reardon MJ, Adams DH, Kleiman NS, Yabukov SJ, Coselli JS, Deeb GM, et al. 2-Year outcomes in patients undergoing surgical or self-expanding transcatheter aortic valve replacement. J Am Coll Cardiol. 2015;66:113-21.
17. Latib A, Maisano F, Bertoldi L, Giacomini A, Shannon J, Cioni M, et al. Transcatheter vs surgical aortic valve replacement in intermediate-surgical-risk patients with aortic stenosis: a propensity score-matched case-control study. Am Heart J. 2012;164:910-7.

18. Johansson M, Nozohoor S, Bjursten H, Ragnarsson S, Gotberg M, Kimblad PO, et al. Late survival and heart failure after transcatheter aortic valve implantation. Asian Cardiovasc Thorac Ann. 2016;24:318-25.

19. Muneretto C, Bisleri G, Moggi A, Di Bacco L, Tespili M, Repossini A, et al. Treating the patients in the 'grey-zone' with aortic valve disease: a comparison among conventional surgery, sutureless valves and transcatheter aortic valve replacement. Interact Cardiovasc Thorac Surg. 2015;20:90-5.

20. Thyregod HG, Steinbruchel DA, Ihlemann N, Nissen H, Kjeldsen BJ, Petrusson $\mathrm{P}$, et al. Transcatheter versus surgical aortic valve replacement in patients with severe aortic valve stenosis: 1-year results from the AllComers NOTION randomized clinical trial. J Am Coll Cardiol. 2015;65: 2184-94.

21. Sondergaard L, Steinbruchel DA, Ihlemann N, Nissen H, Kjeldsen BJ, Petursson $\mathrm{P}$, et al. Two-year outcomes in patients with severe aortic valve stenosis randomized to transcatheter versus surgical aortic valve replacement: the AllComers Nordic Aortic Valve Intervention randomized clinical trial. Circ Cardiovasc Interv. 2016;9:e03665.

22. Reardon MJ, Van Mieghem NM, Popma JJ, Kleiman NS, Sondergaard L, Mumtaz M, et al. Surgical or transcatheter aortic-valve replacement in intermediate-risk patients. $N$ Engl J Med. 2017;376:1321-31.

23. Rosato S, Santini F, Barbanti M, Biancari F, D'Errigo P, Onorati F, et al. Transcatheter aortic valve implantation compared with surgical aortic valve replacement in low-risk patients. Circ Cardiovasc Interv. 2016;9:e003326

24. Thourani VH, Kodali S, Makkar RR, Herrmann HC, Williams M, Babaliaros V, et al. Transcatheter aortic valve replacement versus surgical valve replacement in intermediate-risk patients: a propensity score analysis. Lancet. 2016;387: 2218-25.

25. Barili F, Freemantle N, Folliguet T, Muneretto C, De Bonis M, Czerny M, et al. The flaws in the detail of an observational study on transcatheter aortic valve implantation versus surgical aortic valve replacement in intermediate-risk patients. Eur J Cardiothorac Surg. 2017;51:1031-5.

26. Trochu JN, Le Tourneau T, Obadia JF, Caranhac G, Beresniak A. Economic burden of functional and organic mitral valve regurgitation. Arch Cardiovasc Dis. 2015;108:88-96.

27. Maura G, Blotiere PO, Bouillon K, Billionnet C, Ricordeau P, Alla F, et al. Comparison of the short-term risk of bleeding and arterial thromboembolic events in nonvalvular atrial fibrillation patients newly treated with dabigatran or rivaroxaban versus vitamin K antagonists: a French nationwide propensity-matched cohort study. Circulation. 2015;132: 1252-60.

28. Payet C, Lifante JC, Carty MJ, Rabilloud M, Duclos A. Methodological quality of surgical mortality studies using large hospital databases: a systematic review. Ann Surg. 2017;265:1113-8.

29. Armoiry X, Obadia JF, Iung B, Polazzi S, Duclos A. Clinical outcomes and direc costs after transcatheter aortic valve implantation in French centres: a longitudinal study of 1332 patients using a national database. Interact Cardiovasc Thorac Surg. 2016;23:883-8.

30. Baumgartner H, Falk V, Bax J, De Bonis M, Hamm C, Holm PJ, et al. 2017 ESC/ EACTS guidelines for the management of valvular heart disease. Eur Heart J. 2017;1-53.

31. Nishimura RA, Otto CM, Bonow RO, Carabello BA, Erwin JP III, Fleisher LA, et al. 2017 AHA/ACC focused update of the 2014 AHA/ ACC guideline for the management of patients with valvular heart disease: a report of the American College of Cardiology/American Heart Association task force on clinical practice guidelines. J Am Coll Cardiol. 2017;70: 252-98.

Key Words: French medico-administrative databases, epidemiology, cost, transcatheter aortic valve, surgical aortic valve replacement, aortic stenosis 


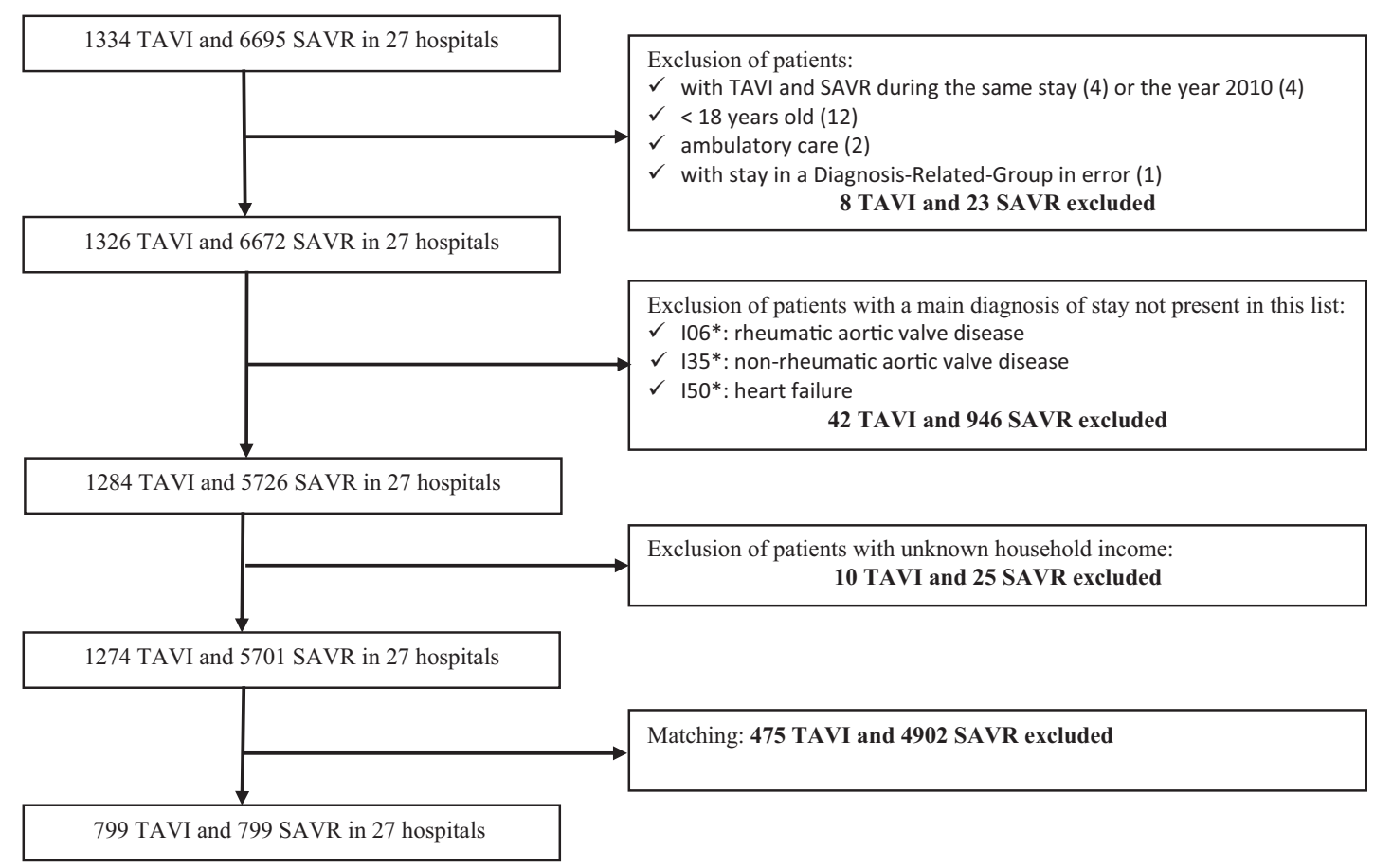

FIGURE E1. Study flowchart. TAVI, Transcatheter aortic valve implantation; SAVR, surgical aortic valve replacement.
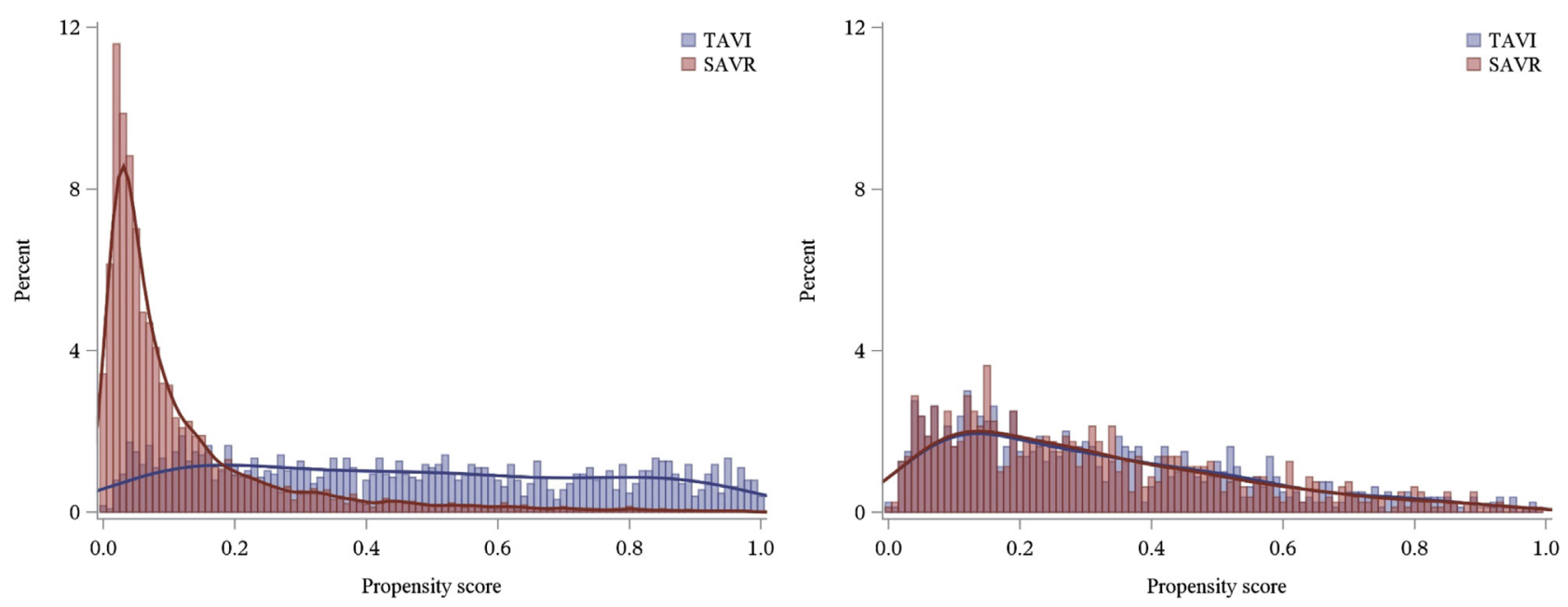

FIGURE E2. Propensity scores distribution before (left) and after (right) matching. TAVI, Transcatheter aortic valve implantation; SAVR, surgical aortic valve replacement. 


\section{Postoperative stay in ICU/CCU}

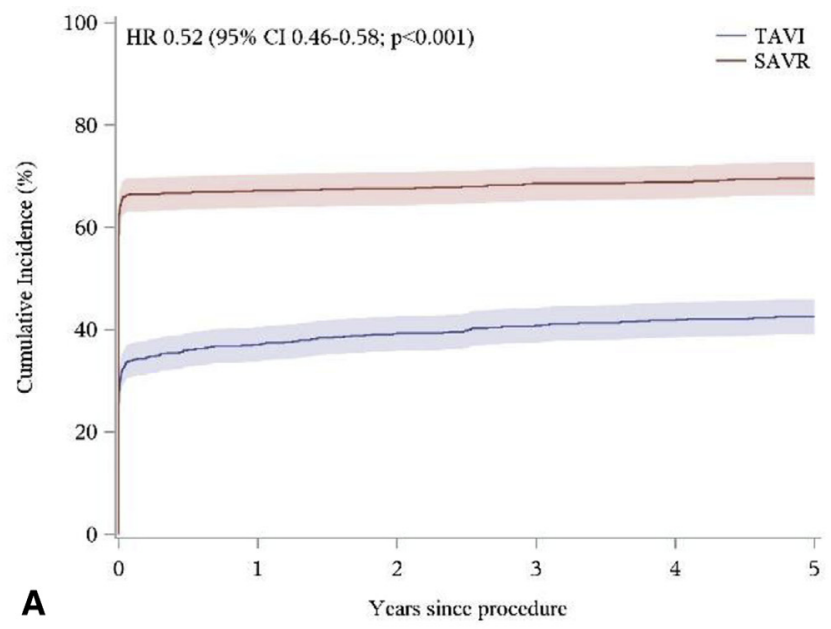

\section{Reoperation}
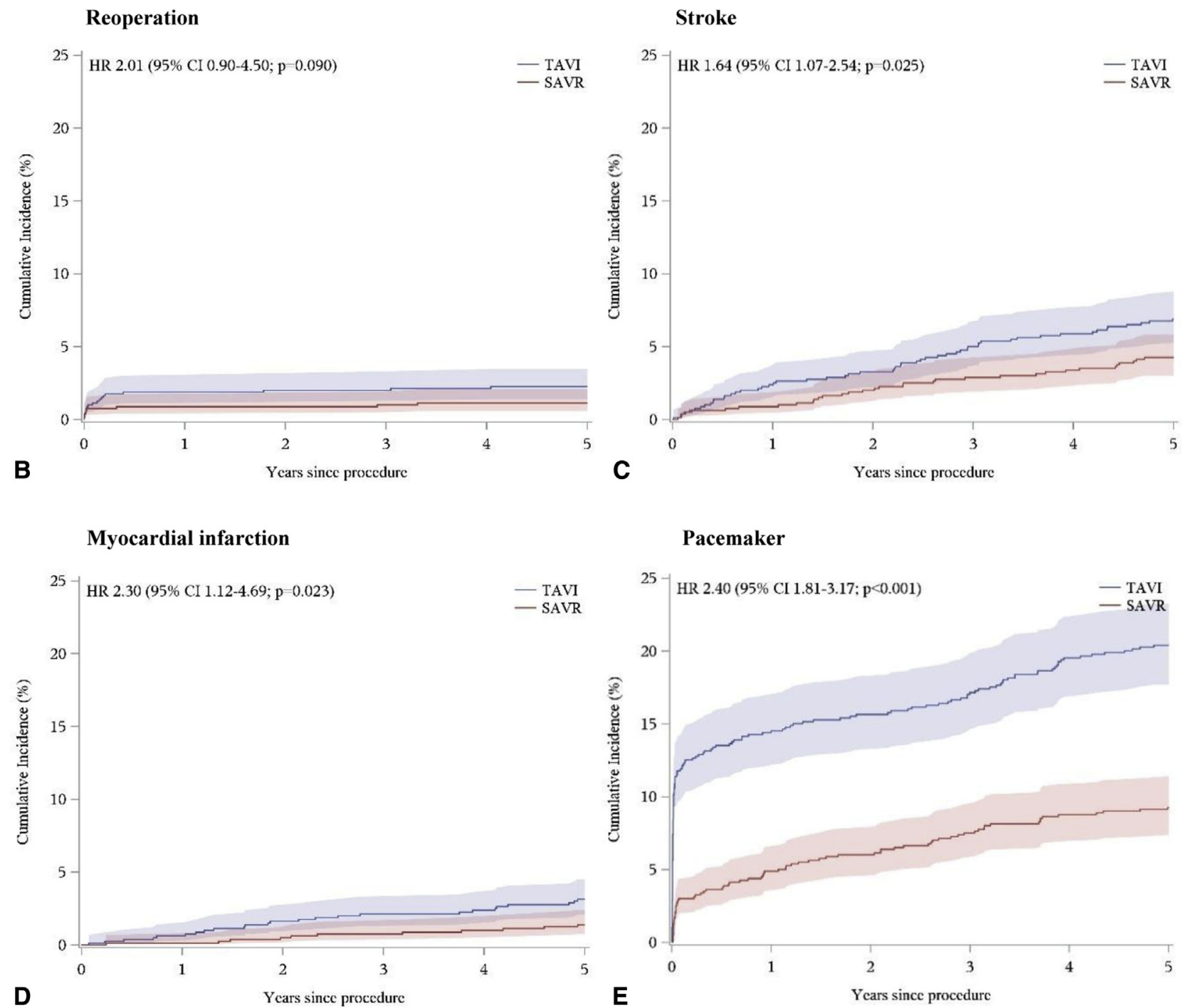

FIGURE E3. Cumulative incidence curves (cumulative probability of events) from the nonparametric cumulative incidence functions estimator using competing risk of death. For readability, scale of vertical axis is not the same between graph (A) and graphs (B), (C), (D), and (E). 


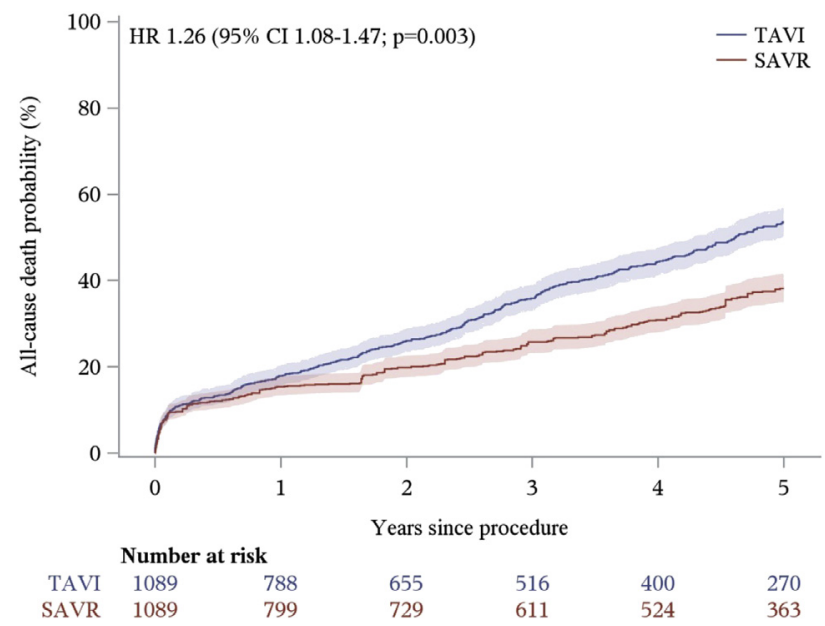

FIGURE E4. Sensitivity analysis (matching with replacement). Cumulative probability of all-cause in-hospital mortality (1-Kaplan-Meier) estimation. Shaded areas are $95 \%$ confidence intervals. TAVI, Transcatheter aortic valve implantation; $S A V R$, surgical aortic valve replacement; $H R$, hazard ratio.

TABLE E1. Baseline characteristics of patients before and after matching

\begin{tabular}{|c|c|c|c|c|c|c|}
\hline \multirow[b]{2}{*}{ Group } & \multicolumn{3}{|c|}{ Prematching } & \multicolumn{3}{|c|}{ Postmatching* } \\
\hline & TAVI $(n=1274)$ & $\begin{array}{c}\text { SAVR } \\
(n=5701)\end{array}$ & $\begin{array}{l}\text { Standardized } \\
\text { difference }\end{array}$ & TAVI $(n=799)$ & $\operatorname{SAVR}(\mathbf{n}=799)$ & $\begin{array}{c}\text { Standardized } \\
\text { difference }\end{array}$ \\
\hline Male sex & $635(49.8)$ & $3485(61.1)$ & 0.229 & $427(53.4)$ & $434(54.3)$ & -0.018 \\
\hline Age, y & $84(79-87)$ & $75(67-80)$ & 1.086 & $81(76-85)$ & $81(77-85)$ & 0.002 \\
\hline Income, $€$ & $\begin{array}{l}19,883 \\
(18,402-22,200)\end{array}$ & $19,573(18,340-21,399)$ & 0.157 & $19,659(18,285-21,971)$ & $19,734(18,395-22,073)$ & -0.060 \\
\hline $\begin{array}{l}\text { No. of days of } \\
\text { hospitalization the } \\
\text { previous years }\end{array}$ & $21.5 \pm 24.5$ & $8.4 \pm 14.0$ & 0.656 & $11(4-23)$ & $10(4-24)$ & -0.006 \\
\hline Emergency procedure & 24 (1.9) & $88(1.5)$ & 0.026 & $13(1.6)$ & $13(1.6)$ & 0.000 \\
\hline Elixhauser & $3(1-4)$ & $3(1-4)$ & 0.050 & $3(1-4)$ & $3(2-4)$ & -0.083 \\
\hline Charlson & $1(0-2)$ & $0(0-2)$ & 0.399 & $1(0-2)$ & $1(0-2)$ & 0.031 \\
\hline Congestive heart failure & $503(39.5)$ & $1259(2.1)$ & 0.384 & $284(35.5)$ & $278(34.8)$ & 0.016 \\
\hline Cardiac arrhythmias & $670(52.6)$ & $3105(54.5)$ & -0.038 & $420(52.6)$ & $427(53.4)$ & -0.018 \\
\hline $\begin{array}{l}\text { Pulmonary circulation } \\
\text { disorders }\end{array}$ & $133(10.4)$ & $261(4.6)$ & 0.224 & $63(7.9)$ & $76(9.5)$ & -0.058 \\
\hline $\begin{array}{l}\text { Peripheral vascular } \\
\text { disease }\end{array}$ & $168(13.2)$ & $437(7.7)$ & 0.181 & $90(11.3)$ & 93 (11.6) & -0.012 \\
\hline Hypertension & $500(39.2)$ & $2746(48.2)$ & -0.181 & $350(43.8)$ & $338(42.3)$ & 0.030 \\
\hline $\begin{array}{l}\text { Chronic pulmonary } \\
\text { disease }\end{array}$ & $141(11.1 \%)$ & $480(8.4 \%)$ & 0.089 & 89 (11.1) & $88(11.0)$ & 0.004 \\
\hline Diabetes & $242(19.0)$ & 1099 (19.3) & -0.007 & 155 (19.4) & $176(22.0)$ & -0.065 \\
\hline Renal disease & $243(19.1)$ & $403(7.1)$ & 0.362 & $122(15.3)$ & 119 (14.9) & 0.010 \\
\hline Liver disease & $30(2.4)$ & $87(1.5)$ & 0.060 & $23(2.9)$ & $21(2.6)$ & 0.015 \\
\hline Obesity & $89(7.0)$ & $691(12.1)$ & -0.175 & $71(8.9)$ & $62(7.8)$ & 0.041 \\
\hline Myocardial infarction & $79(6.2)$ & 208 (3.6) & 0.118 & $52(6.5)$ & $44(5.5)$ & 0.042 \\
\hline Cerebrovascular disease & $107(8.4)$ & $427(7.5)$ & 0.034 & $69(8.6)$ & 79 (9.9) & -0.043 \\
\hline
\end{tabular}

Values are presented as number (\%), median (interquartile range), or mean \pm standard deviation. TAVI, Transcatheter aortic valve implantation; SAVR, surgical aortic valve replacement. *Boldface type indicates variables used in the propensity score model. 
TABLE E2. Compared all-cause death between transcatheter aortic valve implantation and surgical aortic valve replacement cohorts ( $N=1089$ matched pairs $)$

\begin{tabular}{lcc}
\hline Time & $\begin{array}{c}\text { Hazard ratio }(\mathbf{9 5} \% \\
\text { confidence interval)* }\end{array}$ & $\boldsymbol{P}$ value* \\
\hline At 1 y & $1.00(0.79-1.25)$ & .973 \\
At 2 y & $1.05(0.86-1.28)$ & .614 \\
\hline At 3 y & $1.15(0.96-1.37)$ & .124 \\
At 4 y & $1.26(1.07-1.49)$ & .006 \\
At 5 y & $1.26(1.08-1.47)$ & .003 \\
\hline
\end{tabular}

*Hazard ratios (instantaneous rate of event for transcatheter aortic valve implantation relative to surgical aortic valve replacement at any time) ( $95 \%$ confidence interval) and $P$ value, estimated between time 0 and another time point, from Cox proportional hazards model for all-cause death. Matched-pairs design was taken into account with robust variance estimator. Transcatheter aortic valve implantation patients were weighted at 1 and the weight for a surgical aortic valve replacement patient was the number of times it was matched to a transcatheter aortic valve implantation patient.
TABLE E4. Sensitivity analysis (multilevel modeling for the outcomes). Compared all-cause death between transcatheter aortic valve implantation and surgical aortic valve replacement cohorts ( $N=799$ matched pairs $)$

\begin{tabular}{lcr}
\hline Time & $\begin{array}{c}\text { Hazard ratio }(95 \% \\
\text { confidence interval)* }\end{array}$ & $\boldsymbol{P}$ value $^{*}$ \\
\hline At 1 y & $1.34(1.03-1.74)$ & .032 \\
At 2 y & $1.48(1.17-1.86)$ & $<.001$ \\
\hline At 3 y & $1.54(1.26-1.88)$ & $<.001$ \\
At 4 y & $1.60(1.33-1.92)$ & $<.001$ \\
\hline At 5 y & $1.58(1.33-1.87)$ & $<.001$ \\
\hline
\end{tabular}

*Hazard ratios (instantaneous rate of event for transcatheter aortic valve implantation relative to surgical aortic valve replacement at any time) (95\% confidence interval) and $P$ value estimated between time 0 and another time point, from nested frailty model with 2 levels of clustering (matched pairs and hospitals).

TABLE E3. Compared costs between transcatheter aortic valve implantation and surgical aortic valve replacement cohorts ( $N=1089$ matched pairs)

\begin{tabular}{lcc}
\hline Time & $\begin{array}{c}\text { Rate ratio }(\mathbf{9 5} \% \text { confidence } \\
\text { Interval })\end{array}$ & $\boldsymbol{P}$ value* \\
\hline At 1 y & $1.05(0.99-1.11)$ & .104 \\
At 2 y & $1.06(0.99-1.13)$ & .078 \\
At 3 y & $1.06(0.98-1.14)$ & .127 \\
At 4 y & $1.09(1.01-1.17)$ & .028 \\
At 5 y & $1.09(1.01-1.18)$ & .021 \\
\hline
\end{tabular}

*From generalized estimating equation Poisson regression model. Transcatheter aortic valve implantation patients were weighted at 1 and the weight for a surgical aortic valve replacement patient was the number of times it was matched to a transcatheter aortic valve implantation patient. 